\title{
CLUSTERING HASIL TANGKAP IKAN DI PELABUHAN PERIKANAN NUSANTARA (PPN) TERNATE MENGGUNAKAN ALGORITMA K- MEANS
}

\author{
Rofika Julianti Hablum ${ }^{1}$, Amal Khairan², Rosihan ${ }^{3}$ \\ Program Studi Teknik Informatika, Fakultas Teknik, Universitas Khairun \\ Jl. Jati Metro, Kota Ternate Selatan \\ E-mail: rofika.julianti.hablum28@gmail.com ${ }^{1}$, ibntawakkal@gmail.com², rosihan.unkhair@outlook.com ${ }^{3}$
}

This research aims to classifying (clustering) the results of catching fish per month for the period to 2015 to 2017 by using the $k$-means algorithm and determine the most superior fish.Therefore the existence of this research by using the algorithm of K-means clustering can assist to provide the information about superior species of fish or the most abundant species and fish that appear less in the sea waters of Ternate, in order to facilitate the fishermen in preparing for arrest next fish. Data taken by the PPN Ternate is the monthly fishing catch data for the 2015 to 2017 period. Cluster evaluation methods use the DBI method (Davies Bouldin Index) to find out how good or good clusters are used in the research, the authors have calculated several clusters, namely 2 cluster, 3 cluster, 4 cluster, and 5 cluster to determine the comparison, the result is the DBI value in 2 cluster which is closest to value of 0 . The DBI value obtained in 2 clusters in $2015=0.395$, year 2016 = 0.276, and in $2017=0.54$. The results of the research used 18 fish data to produce 2 clusters, which there were 16 data entered cluster one (C1) and 2 data that goes into the cluster two (C2.

\section{Keywords: Fish, Cluster, K-means, DBI (Davies Bouldin Index)}

Abstrak - Penelitian ini bertujuan untuk mengelompokkan (clustering) hasil tangkap ikan perbulan periode 2015 sampai 2017 menggunakan algoritma $k$-means dan menentukan ikan yang paling unggul. Maka dari itu dengan adanya penelitian ini dengan menggunakan algoritma $k$-means clustering dapat sedikit membantu dalam memberikan informasi tentang jenis ikan apa yang unggul atau jenis ikan yang paling banyak maupun ikan yang sedikit muncul pada perairan laut Ternate, agar dapat mempermudah para nelayan dalam mempersiapkan penangkapan ikan selanjutnya. Data yang diambil pada PPN Ternate yaitu data hasil tangkap ikan perbulan periode 2015 sampai 2017. Metode evaluasi cluster menggunakan metode DBI (Davies Bouldin Index) untuk mengetahui seberapa bagus atau baik cluster yang dipakai pada penelitian, penulis sudah melakukan perhitungan beberapa cluster, yaitu 2 cluster, 3 cluster, 4 cluster, dan 5 cluster untuk menentukan perbandingan, hasilnya adalah nilai DBI pada 2 cluster yang paling mendekati nilai 0. Nilai DBI yang didapat pada 2 cluster tahun $2015=0,395$, tahun $2016=0,276$, dan tahun $2017=$ 0,54. Hasil penelitian menggunakan 18 data ikan dengan menghasilkan 2 cluster, dimana ada 16 data yang masuk pada cluster satu $\left(\mathrm{C}_{1}\right)$ dan 2 data yang masuk pada cluster dua $\left(\mathrm{C}_{2}\right)$.

Kata Kunci: Ikan, Cluster, K-means, DBI (Davies Bouldin Index). 


\section{PENDAHULUAN}

\subsection{Latar Belakang}

Wilayah lautan merupakan kawasan terluas dan memiliki aneka ragam hayati laut serta kekhasannya yang berbeda dengan wilayah daratan di Indonesia. Dengan luasnya lautan, banyaknya pulau-pulau besar dan kecil menjadikan Indonesia sebagai wilayah berpotensi di sektor perikanan. Perikanan merupakan salah satu bidang yang diharapkan mampu menjadi penopang peningkatan kesejahteraan rakyat Indonesia. Sub sektor perikanan dapat berperan dalam pemulihan dan pertumbuhan perekonomian, karena potensi sumberdaya ikan yang besar dalam jumlah dan keragamannya.

Ternate adalah sebuah kota yang berada di bawah kaki gunung api Gamalama (1.025 $\mathrm{m}$ di atas permukaan laut) yang terletak di pulau Ternate. Secara administratif, Ternate berada di provinsi Maluku Utara, Indonesia. Kota Ternate merupakan kota kepulauan yang memiliki luas daratan sebesar 162,03 km², sementara luas lautannya $5.547,55 \mathrm{~km}^{2}$ [1]. Potensi dari Kota Ternate di sektor perikanan sangatlah besar dilihat berdasarkan pada data statistik Pelabuhan Perikanan Nusantara (PPN) Ternate.

PPN (Pelabuhan Perikanan Nusantara) Ternate adalah salah satu pelabuhan perikanan yang lokasinya cukup strategis berada di dalam kota tepatnya berada di jalan Pasar Inpres, Kelurahan Bastiong Talangame Kecamatan Ternate Selatan Kota Ternate Provinsi Maluku Utara. Akses menuju sarana penunjang seperti bandara dan pelabuhan umum dapat dijangkau dengan mudah.

Secara geografis PPN Ternate terletak pada posisi $0046^{\prime} 0,36$ "LU dan 127 22' 41,10" BT (Statistik Perikanan Tang kap PPN Ternate, 2015).

Pelabuhan Perikanan Nusantara Ternate dibangun pada tahun 1978 dengan berbagai sarana dasar, sarana fungsional, dan sarana penunjang. PPN Ternate pada awal berdirinya adalah Pelabuhan Perikanan pantai. Pada pertengahan tahun 2001 dinaikkan statusnya menjadi Pelabuhan Perikanan Nusantara. Hal tersebut didasarakan pada perkembangan operasional PPN Ternate yang terus mengalami peningkatan dari tahun ke tahun [2]. Volume tangkap ikan dari tahun ke tahun pada PPN Ternate mengalami kenaikan dengan menggunakan beberapa alat tangkap seperti purse Seine, Hand Line, Pole and Line, dan giop. Adapun jenis ikan hasil tangkap PPN Ternate adalah ikan cakalang, tongkol, ekor kuning, kembung, madidihang, selar, cumi, tembang, julung-julung, sarden, sunglir, kakap, kerapu, lencam, lolosi, kwee, beronang, cendro, biji nangka, dan swanggi.

Berdasarkan uraian diatas, permasalahan yang di temukan yaitu dengan banyak ragamnya jenis ikan hasil tangkap pada PPN Ternate belum diketahui jenis ikan apa yang unggul disetiap tahunnya, disamping itu juga belum terkelompokan jenis ikan apa yang paling banyak dan sedikit hasil tangkapnya. Maka dari itu dilakukan penelitian untuk Clustering Hasil Tangkap
Ikan Di Pelabuhan Perikanan Nusantara (Ppn) Ternate Menggunakan Algoritma KMeans", selain itu dilakukan validasi dengan davies bouldin index sebagaimana pernah dilakukan oleh [9] pada pemetaan potensi udang.

Clustering adalah suatu metode untuk mencari dan mengelompokkan data yang memiliki kemiripan karakteristik (similarity) antara satu data dengan yang lain. Clustering merupakan salah satu metode data mining yang bersifat tanpa arahan (unsupervised), maksudnya metode ini diterapkan tanpa adanya latihan (training) dan tanpa ada guru (teacher) serta tidak memerlukan target output.

K-Means merupakan salah satu metode data clustering non-hirarki yang mengelompokkan data dalam bentuk satu atau lebih cluster/kelompok. Datadata yang memiliki karakteristik yang berbeda dikelompokkan dengan cluster yang lain sehingga data yang ada dalam satu kelompok memiliki tingkat variasi yang kecil [3].

\subsection{Tujuan Penelitian}

1. Mengelompokkan (clustering) hasil tangkap jenis ikan perbulan periode 2015-2017 menggunakan algoritma K-Means dan menentukan ikan yang paling unggul.

2. Membangun aplikasi menggunakan pemrograman PHP untuk implementasi algoritma $K$-Means.

\subsection{Manfaat Penelitian}

1. Sebagai informasi untuk pengelolaan jenis ikan pada perikanan tangkap di PPN Ternate.

2. Sebagai bahan acuan dan petunjuk untuk merencanakan operasi penangkapan ikan bagi sektor perikanan khususnya PPN Ternate.

3. Bahan masukan bagi perguruan tinggi yang berada dikota ternate maupun diluar daerah baik negeri maupun swasta yang memilki program studi Perikanan mengenai clustering hasil tangkap ikan menggunakan algoritma $K$-Means.

\section{TINJAUAN PUSTAKA}

\subsection{Data Mining}

Data mining adalah suatu kegiatan yang meliputi pengumpulan, pemakaian data historis untuk menentukan keteraturan, pola atau hubungan dalam set data berukuran besar. Salah satu tugas utama dalam data mining adalah pengelompokkan clustering dimana data yang dikelompokkan belum mempunyai contoh kelompok .

Data mining adalah suatu proses pencarian korelasi, pola dan tren baru yang berguna dalam media penyimpanan data berukuran besar menggunakan 
teknologi pengenalan pola seperti teknik-teknik statistik dan matematis [4].

\subsection{Normalisasi}

Normalisasi adalah proses pengskalaan nilai atribut dari data sehingga bisa jatuh pada range tententu. Pada proses normalisasi dilakukan dengan metode Min-Max, yaitu metode normalisasi dengan melakukan transformasi linier terhadap data asli, berikut persamaan pada metode Min-Max:

nilai normalisasi $=\frac{X a w a l-X \min }{X \max -X \min }$ .1

Keterangan:

Xawal $=$ nilai awal

$\mathrm{X} \max =$ nilai maksimal atau nilai terbesar

$\mathrm{Xmin}=$ nilai minimal atau nilai terkecil [5].

\subsection{Clustering}

Pada dasarnya clustering merupakan suatu metode untuk mencari dan mengelompokkan data yang memiliki kemiripan karakteristik (similarity) antara satu data dengan data yang lain. Clustering merupakan salah satu metode data mining yang bersifat tanpa arahan (unsupervised), maksudnya metode ini diterapkan tanpa adanya latihan (training) dan tanpa ada guru (teacher) serta tidak memerlukan target output. Dalam data mining ada dua jenis metode clustering yang digunakan dalam pengelompokkan data, yaitu hierarchical clustering dan nonhierarchical clustering.

Hierarchical clustering adalah suatu metode pengelompokkan data yang dimulai dengan mengelompokkan dua atau lebih objek yang memiliki kesamaan paling dekat. Kemudian proses diteruskan pada objek lain yang memiliki kedekatan kedua. Demikian seterusnya kemudian cluster akan membentuk semacam pohon dimana ada hierarki (tingkatan) yang jelas antar objek, dari yang paling mirip sampai yang paling tidak mirip. Secara logika semua objek pada akhirnya hanya akan membentuk sebuah cluster.

Berbeda dengan metode hierarchical clustering, metode non-hierarchical clustering justru dimulai dengan menentukan terlebih dahulu jumlah cluster yang diinginkan (dua cluster, tiga cluster, atau lain sebagainya). Setelah jumlah cluster diketahui, baru proses cluster dilakukan tanpa mengikuti proses hierarki. Metode ini biasa disebut dengan k-means clustering [3].

\subsection{Algoritma K-means}

K-Means merupakan salah satu metode data clustering non-hirarki yang mengelompokkan data dalam bentuk satu atau lebih cluster/kelompok. Datadata yang memiliki karakteristik yang berbeda dikelompokkan dengan cluster yang lain sehingga data yang ada dalam satu kelompok memiliki tingkat variasi yang kecil [3].

Algoritma k-means juga termasuk metode Partitioning Method, yaitu membangun berbagai partisi dan kemudian mengevaluasi partisi tersebut dengan beberapa kriteria [4].

Berikut rumus pengukuran jarak dalam algoritma k-means:

$$
d_{(x, y)}=\sqrt{(x i-y i)^{2}+(x i-y i)^{2}}
$$

\section{Keterangan:}

$\mathrm{d}=$ titik dokumen

$\mathrm{x}=$ data record

$\mathrm{y}=$ data centroid

Jarak yang terpendek antara centroid dengan dokumen menentukan posisi cluster suatu dokumen. Misalnya dokumen A mempunyai jarak yang paling pendek ke centroid 1 dibanding ke yang lain, maka dokumen A masuk ke group 1. Hitung kembali posisi ke centroid baru untuk tiap-tiap centroid $\left(\mathrm{C}_{\mathrm{i}-\mathrm{j}}\right)$ dengan mengambil rata-rata dokumen yang masuk pada cluster awal $\left(\mathrm{G}_{\mathrm{i}-\mathrm{j}}\right)$. Iterasi dilakukan terus hingga posisi group tidak berubah (Dwi, 2012). Berikut rumus dari penentuan centroid:

$$
C(i)=\frac{x_{1}+x_{2}+x_{. .}+x_{. .}}{\sum x}
$$
3

Keterangan:

$x_{1}=$ nilai data record $\mathrm{ke}-1$

$x_{2}=$ nilai data record $\mathrm{ke}-2$

$\sum x=$ jumlah data record

Proses algoritma K-means sebagai berikut:

a. Pilih secara acak objek sebanyak k, objek-objek tersebut akan dipresentasikan sebagai mean pada cluster.

b. Untuk setiap objek dimasukan kedalam cluster yang tingkat kemiripan objek terhadap cluster tersebut tinggi. Tingkat kemiripan ditentukan dengan jarak objek terhadap mean atau centroid cluster tersebut.

c. Hitung nilai centroid yang baru pada masingmasing cluster.

d. Proses tersebut diulang hingga anggota pada kumpulan cluster tersebut tidak berubah.

\subsection{Davies Bouldin Index}

Davies Bouldin Index (DBI) adalah cara validasi cluster yang dibuat oleh D.L. Davies. DBI merupakan salah satu metode evaluasi cluster pada suatu metode pengelompokan yang didasarkan pada nilai kohesi dan separasi. Dalam suatu pengelompokan, kohesi didefinisikan sebagai jumlah dari kedekatan data terhadap centroid dari cluster yang diikuti. Sedangkan separasi didasarkan pada jarak antar centroid dari clusternya.

Sum of square within (SSW) cluster merupakan persamaan yang digunakan untuk mengetahui matrik kohesi dalam sebuah cluster ke-i yang dirumuskan sebagai berikut:

$$
S S W_{i}=\frac{1}{m_{i}} \sum_{j=i}^{m_{i}} d\left(x_{j}, c_{i}\right)
$$

Keterangan:

$m_{i}=$ jumlah data dalam cluster ke-i

$c_{i}=$ centroid cluster $\mathrm{ke}-\mathrm{i}$ 
$d()=$ jarak setiap data ke centroid yang dihitung menggunakan jarak euclidean

Sum of square between cluster (SSB) merupakan persamaan yang digunakan untuk mengetahuai separasi antar cluster

yang dihitung menggunakan persamaan:

$S S B_{i, j}=d\left(c_{i}, c_{j}\right)$ .5

Setelah nilai kohesi dan separasi diperoleh, kemudian dilakukan pengukuran rasio $\left(R_{I J}\right)$ untuk mengetahui nilai perbandingan antara cluster ke-I dan cluster ke-j. Cluster yang baik adalah cluster yang memiliki nilai kohesi sekecil mungkin dan separasi yang sebesar mungkin. Nilai rasio dihitung menggunakan persamaan berikut:

$$
R_{i j}=\frac{S S W_{i}+S S W_{j}}{S S B_{i, j}}
$$

Nilai rasio yang diperoleh tersebut digunakan untuk mencari nilai davies bouldin index (DBI) dari persamaan berikut:

$$
D B I=\frac{1}{k} \sum_{i=1}^{k} \max _{i \neq j}\left(R_{i, j}\right)
$$

Dari persamaan tersebut, $\mathrm{k}$ merupakan cluster yang digunakan. Semakin kecil nilai DBI yang diperoleh (non-negatif $>=0$ ), maka semakin baik cluster yang diperoleh dari pengelompokan K-Means yang digunakan [6].

\section{Metode Penelitian}

\subsection{Metode Pengembangan Perangkat Lunak}

Dalam penelitian ini, metode pengembangan perangkat lunak yang digunakan yaitu metode prototype, sebagai alat bantu dalam memberi gambaran sistem seperti materi dan menu yang perlu dimasukan dalam prototyping yang akan dikembangkan. Berikut tahapan prototype yang dibuat:

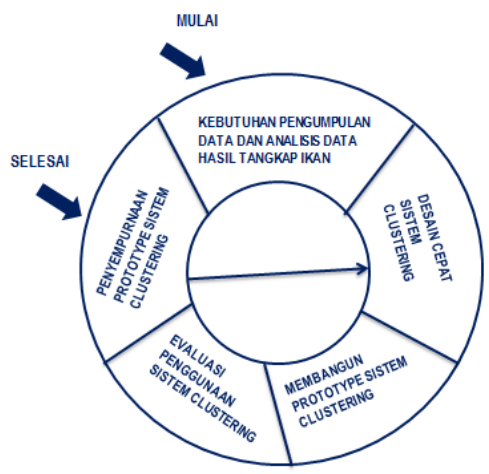

Gambar 1 Tahapan Prototype Clustering Hasil Tangkap Ikan

Adapun tahapan prototype clustering hasil tangkap ikan sebagai berikut:
1. Kebutuhan Pengumpulan dan Analisis Data Hasil Tangkap Ikan

Mengumpulkan kebutuhan sistem yaitu dengan mengambil data penelitian di PPN Ternate kemudian hasilnya di analisa untuk menentukan kebutuhan sistem.

2. Desain yang Cepat Sistem Clustering

Setelah menentukan kebutuhan sistem maka dilakukan desain secara cepat dengan pemodelan DFD dan ERD dari sistem clustering tangkap ikan.

3. Membangun Protototype Sistem Clustering Dari desain yang di pergunakan dibuat program yang merepresentasikan sistem untuk mengclustering hasil produksi ikan dengan menerapkan algoritma $\mathrm{K}$-Means

4. Evaluasi Pengguna Sistem Clustering

Pengguna diminta untuk melakukan uji coba sistem clustering agar diketahui kelebihan dan kekurangan, pada tahap ini segala informasi dari pengguna sistem clustering dicatat untuk diberikan ke pembuat sistem clustering.

5. Penyempurnaan Prototype Sistem Clustering Jika hasil dari evaluasi pengguna sistem mengclustering hasil produksi ikan tidak puas maka dilakukan penyempurnaan sistem sesuai dengan permintaan pengguna, kemudian kembali melakukan desain secara cepat (langkah 2), dan lanjut ke langkah berikutnya. Jika masih ditemukan kekurangan pada tahap evaluasi pengguna. Maka dilakukan perbaikan lagi dari langkah 2. Proses akan berhenti jika Pengguna sudah tidak menemukan kekurangan pada sistem clustering produksi ikan.

3.2. Pengumpulan Data

1. Observasi

Peneliti melakukan observasi langsung ke Kantor Dinas PPN Ternate untuk mengambil data yang ada. Dengan demikian, peneliti dapat mengetahui data yang terkait dengan judul ini.

2. Studi Literatur

Pada studi literatur dimana peneliti mengambil dari jurnal yang terkait dengan judul penelitian. Seperti halnya jurnal tentang clustering data mining yang menggunakan metode seperti $K$-Means.

Dalam penelitian ini, terdapat dua jenis data, yaitu:

a. Data primer

Data primer dalam penelitian ini adalah data yang diambil dari Kantor Dinas PPN Ternate. Data yang dipergunakan oleh peneliti adalah data akomodasi hasil tangkap ikan perbulannya selama periode 2015 sampai 2017.

b. Data sekunder

Data sekunder yang dipergunakan dalam penelitian ini adalah teori-teori, penelitian 
terdahulu, maupun keterangan-keterangan dari ahli yang berkompeten yang bersumber dari internet yang berisikan tentang berita terkini mengenai jenis-jenis ikan di Indonesia.

\subsection{Diagram Alir Prosedur Penelitian}

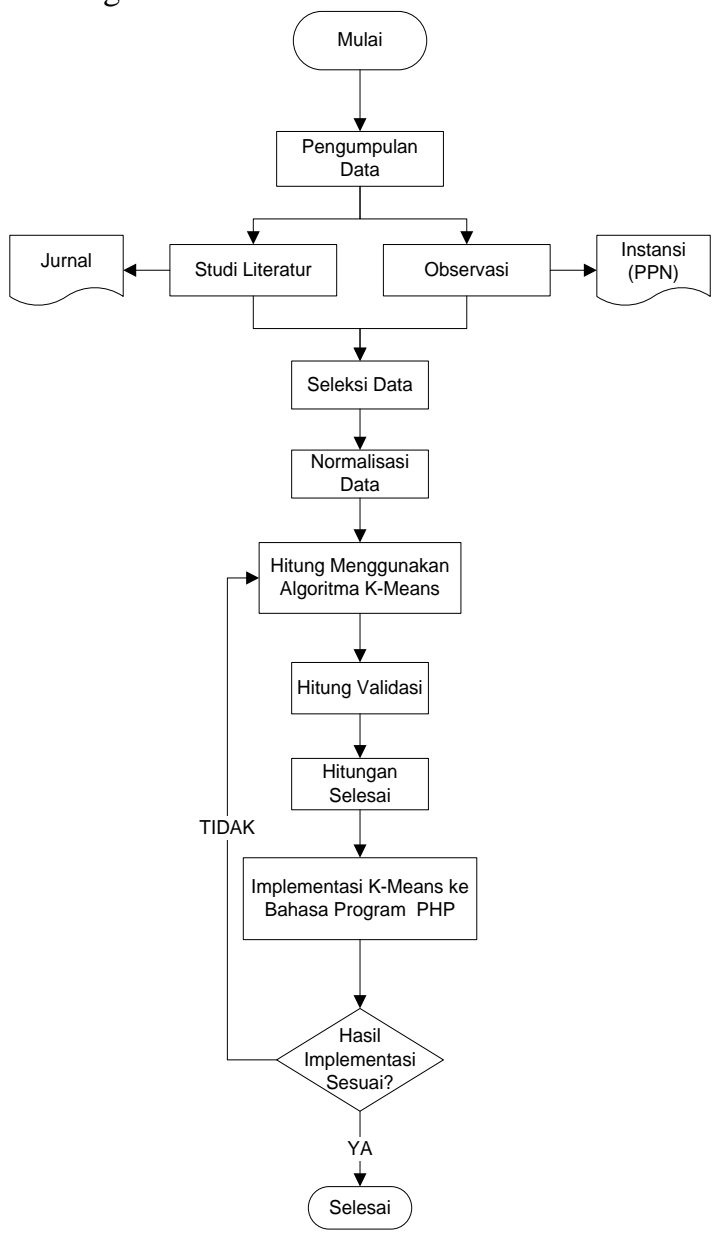

Gambar 2 Diagram Alir Penelitian

Lamgkah - langkah diagram alir penelitian:

1. Pengumpulan Data

Peneliti mengambil data penelitian dengan observasi yaitu dengan mengambil data langsung ke instansi terkait dengan judul penelitian yakni PPN Ternate, sedangkan studi literatur yaitu peneliti mengambil data pada jurnal yang terkait dengan algoritma $K$-Means.

2. Seleksi Data

Untuk memilih himpunan data (dataset) yang akan digunakan pada penulisan ini, yaitu data hasil tangkap ikan perbulan selama periode 2015-2017.

3. Normalisasi Data

Sebelum data dihitung menggunakan algoritma $k$-means, semua data hasil tangkap ikan tahun 2015 sampai tahun 2017 dinormalisasi terlebih dahulu karena adanya pebedaan besaran angka yang cukup jauh pada masing-masing variabel data.

4. Hitung Clustering Menggunakan Algoritma KMeans.
Tahapan proses dimana data yang sudah dinormalisasi akan dihitung dan cluster dengan menggunakan cara kerja algoritma K-Means. Sebelum data dihitung peneliti menentukan kriteria sesuai dengan tahap K-Means. Karena yang akan dihitung adalah hasil tangkap ikan perbulan, maka dapat ditentukan kriteria yaitu: Januari, Februari, Maret, April, Mei, Juni, Juli, Agustus, September, Oktober, November, dan Desember.

5. Validasi Data

Setelah proses clustering menggunakan algoritma $k$-means selesai, maka data centroid akhir pada tahap k-means akan di hitung menggunakan metode DBI (Davies Bouldien Index) untuk menentukan cluster terbaik yang digunakan pada penelitian ini.

6. Implementasi K-Means Menggunakan Bahasa Program PHP

Pada tahap dimana data yang sudah dihitung menggunakan tahap $K$-Means akan diuji dalam program menggunakan bahasa pemrograman PHP.

7. Hasil Pengujian Sesuai?

Pada tahap ini, jika hasil pengujian program tidak sesuai, maka diperbaiki bahasa program PHPnya, kemudian diuji lagi, jika belum sesuai maka kembali ke hitungan menggunakan tahap $K$-Means lalu diuji lagi dengan program, setelah hasil pengujian program sesuai, maka dilanjutkan ke kesimpulan.

\subsection{Analisis Sistem Algoritma K-means}

Didalam pembuatan laporan ini menggunakan algoritma $k$-means untuk menyelesaikan masalah penentuan cluster pada masing-masing jenis ikan hasil tangkap pada PPN Ternate dan penentuan keunggulan ikan pertahun. Sebelum tahap menghitung algoritma $k$-means menggunakan rumus pengukuran jarak (untuk mencari nilai pusat klaster atau centroid yang cocok), ditentukan kriteria terlebih dahulu, ada 12 kriteria yang ditentukan yaitu, bulan Januari, Februari, Maret, April, Mei, Juni, Juli, Agustus, Sepetember, Oktober, November, dan Desember. setelah hasil nilai pengukuran jarak didapat, maka akan ditentukan letak masing-masing klaster dalam bentuk tabel. Nilai pusat cluster akan didapat pada beberapa iterasi hingga nilai cluster tidak berpindah pada iterasi terakhir dan sudah terbagi menjadi dua cluster.

Sistem yang akan dibangun pada penelitian ini secara umum digunakan untuk mengimplementasikan hasil hitungan algoritma $k$-means, selain itu sistem ini juga dapat memberikan informasi yang dibutuhkan oleh pengguna, misalnya akan ditampilkan hasil cluster yang sudah dibentuk dan ikan yang paling unggul pada jenis-jenis ikan hasil tangkap pada instansi terkait, sehingga informasi tersebut dapat dimanfaatkan untuk memberitahukan misalnya kepada para nelayan, ikan apa yang paling unggul atau jenis ikan yang paling banyak, sehingga para nelayan sudah bisa mempersiapkan jenis alat tangkap ikan 
yang sesuai (misalnya jaring lingkar/ purse seine digunakan untuk menangkap ikan tongkol, layang, cakalang, kembung) dalam melakukan atau merencanakan penangkapan ikan selanjutnya yang dianggap paling unggul atau paling banyak terlihat diperairan Ternate.

\subsection{Metode Pengujian Sistem}

Pengujian perangkat lunak digunakan untuk mengetahui apakah perangkat lunak dapat berjalan dengan baik atau tidak, dalam penelitian ini pengujian perangkat lunak yang digunakan adalah Black box. Black box testing digunakan untuk mengetahui apakah program yang dibuat sudah sesuai dengan kebutuhan fungsionalnya atau tidak. Skenario pengujian dapat dilihat pada tabel 1 .

Tabel 1 Skenario Pengujian

\begin{tabular}{|l|l|l|l|}
\hline No & Kelas Uji & Butir Uji & $\begin{array}{l}\text { Jenis } \\
\text { Pengujian }\end{array}$ \\
\hline 1 & Login & $\begin{array}{l}\text { Verifikasi } \\
\text { username }\end{array}$ & Blackbox \\
\cline { 3 - 4 } & $\begin{array}{l}\text { Verifikasi } \\
\text { password }\end{array}$ & \\
\hline 2 & $\begin{array}{l}\text { Input Centroid } \\
\text { Awal }\end{array}$ & $\begin{array}{l}\text { Input data } \\
\text { centroid } \\
\text { awal }\end{array}$ & Blackbox \\
\hline 3 & Input Dataset & $\begin{array}{l}\text { Input data } \\
\text { tahun } \\
\text { selanjutnya }\end{array}$ & Blackbox \\
\hline
\end{tabular}

\section{HASIL DAN PEMBAHASAN}

\subsection{Flowchart Algoritma K-means}

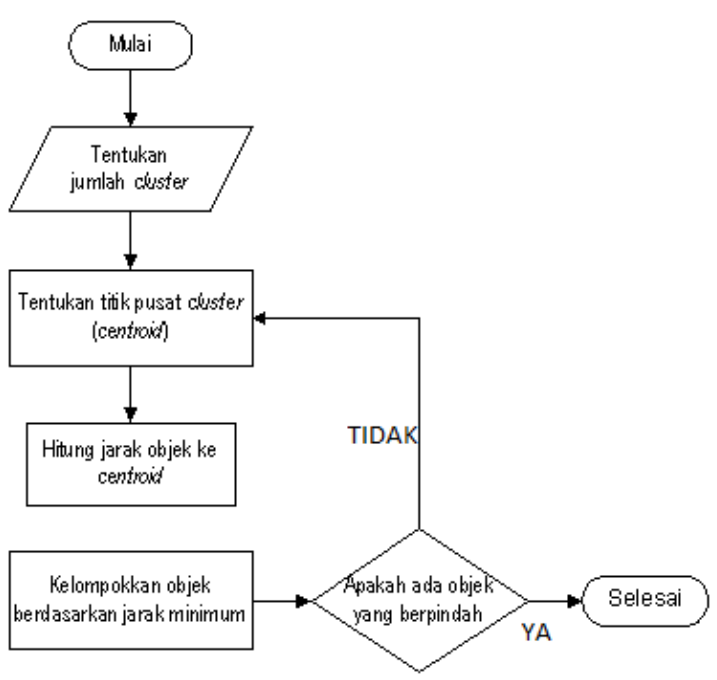

Gambar 4 Flowchart Algoritma K-means

\section{Algoritma k-means:}

1. Menentukan jumlah cluster, yaitu ada dua cluster pada penelitian dengan cluster pertama $\left(\mathrm{C}_{1}\right)$ dikategorikan sebagai sedikit dan cluster kedua $\left(\mathrm{C}_{2}\right)$ dikategorikan sebagai banyak.

2. Menentukan pusat cluster atau centroid awal disesuaikan dengan jumlah variabel yang ada. Jumlah variabel yang ditentukan peneliti sebanyak 12 yaitu: Januari, Februari, Maret, April, Mei, Juni, Juli, Agustus, September, Oktober, November, dan Desember. Maka nilai centroid awal pada masing-masing cluster harus 12 data.

3. Menghitung jarak objek ke cenrtoid dengan menggunakan rumus pengukuran jarak.

4. Mengelompokkan objek kedalam cluster berdasarkan jarak minimum dalam bentuk tabel, jika objek mengalami perpindahan pada tahap ini maka kembali ke proses ke-2, dan apabila objek tidak mengalami perpindahan maka perhitungan selesai, maka lanjut ke kesimpulan.

4.2. Hasil Hitung K-means dengan 2 Cluster Periode 2015 sampai 2017

Tabel 2 Posisi Cluster Iterasi Terakhir Tahun 2015

\begin{tabular}{|c|l|l|l|c|}
\hline No & Jenis Ikan & $\mathbf{C}_{\mathbf{1}}$ & $\mathbf{C}_{\mathbf{2}}$ & $\begin{array}{c}\text { Posisi } \\
\text { Cluster }\end{array}$ \\
\hline 1 & Layang & 1,790 & 0,813 & $\mathbf{C 2}$ \\
\hline 2 & Tembang & 0,142 & 2,669 & $\mathbf{C 1}$ \\
\hline 3 & Cakalang & 3,323 & 0,813 & $\mathbf{C 2}$ \\
\hline 4 & Tongkol krai & 1,052 & 1,962 & $\mathbf{C 1}$ \\
\hline 5 & Kembung & 0,269 & 2,392 & $\mathbf{C 1}$ \\
\hline 6 & Madidihang & 0,235 & 2,440 & $\mathbf{C 1}$ \\
\hline 7 & Julung & 0,144 & 2,672 & $\mathbf{C 1}$ \\
\hline 8 & Lencam & 0,09 & 2,524 & $\mathbf{C 1}$ \\
\hline 9 & Teri & 0,132 & 2,665 & $\mathbf{C 1}$ \\
\hline 10 & Kakap & 0,082 & 2,522 & $\mathbf{C 1}$ \\
\hline 11 & Kerapu & 0,063 & 2,533 & $\mathbf{C 1}$ \\
\hline 12 & Baronang & 0,08 & 2,604 & $\mathbf{C 1}$ \\
\hline 13 & Kwee & 0,067 & 2,526 & $\mathbf{C 1}$ \\
\hline 14 & Tenggiri & 0,153 & 2,682 & $\mathbf{C 1}$ \\
\hline 15 & Biji nanggka & 0,133 & 2,664 & $\mathbf{C 1}$ \\
\hline 16 & Selar & 0,137 & 2,667 & $\mathbf{C 1}$ \\
\hline 17 & Swanggi & 0,111 & 2,646 & $\mathbf{C 1}$ \\
\hline 18 & Lolosi biru & 0,153 & 2,682 & $\mathbf{C 1}$ \\
\hline
\end{tabular}

Deskripsi:

1. Cluster pertama memiliki pusat $(0,064 ; 0,078$; 0,$042 ; 0,034 ; 0,031 ; 0,041 ; 0,033 ; 0,03 ; 0,019$; $0,022 ; 0,042 ; 0,056)$ yang dapat diartikan sebagai sedikit. Ada 16 ikan yang termasuk kelompok ini, yaitu ikan Tembang, Tonkogkol krai, Kembung, Madidihang, Julung, Lencam, Teri, Kakap, Kerapu, Baronang, Kwee, Tenggiri, Biji nangka, Selar, Swanggi, Lolosi biru.

2. Cluster kedua memiliki pusat $(0,774 ; 0,729$; 0,$836 ; 0,807 ; 0,74 ; 0,751 ; 0,81 ; 0,852 ; 0,813$; $0,642 ; 0,714 ; 0,803)$ yang dapat diartikan sebagai banyak. Ada 2 ikan yang termasuk dalam kelompok ini yaitu ikan Layang dan Cakalang. 
Tabel 3 Posisi Cluster Iterasi Terakhir Tahun 2016

\begin{tabular}{|c|l|c|c|c|}
\hline No & Jenis Ikan & C1 $_{1}$ & $\mathbf{C}_{2}$ & $\begin{array}{c}\text { Posisi } \\
\text { Cluster }\end{array}$ \\
\hline 1 & Layang & 2,632 & 0,639 & C2 \\
\hline 2 & Tembang & 0,122 & 2,948 & C1 \\
\hline 3 & Cakalang & 3,151 & 0,639 & C2 \\
\hline 4 & Tongkol krai & 0,129 & 2,956 & C1 \\
\hline 5 & Kembung & 0,345 & 2,555 & C1 \\
\hline 6 & Madidihang & 0,434 & 2,470 & C1 \\
\hline 7 & Julung & 0,107 & 2,934 & C1 \\
\hline 8 & Lencam & 0,126 & 2,719 & C1 \\
\hline 9 & Teri & 0,128 & 2,955 & C1 \\
\hline 10 & Kakap & 0,113 & 2,735 & C1 \\
\hline 11 & Kerapu & 0,085 & 2,761 & C1 \\
\hline 12 & Baronang & 0,081 & 2,902 & C1 \\
\hline 13 & Kwee & 0,082 & 2,763 & C1 \\
\hline 14 & Tenggiri & 0,129 & 2,955 & C1 \\
\hline 15 & Biji nanggka & 0,087 & 2,913 & C1 \\
\hline 16 & Selar & 0,105 & 2,927 & C1 \\
\hline 17 & Swanggi & 0,076 & 2,892 & C1 \\
\hline 18 & Lolosi biru & 0,126 & 2,953 & C1 \\
\hline
\end{tabular}

\section{Deskripsi:}

1. Cluster pertama memiliki pusat $(0,042 ; 0,052$; 0,$042 ; 0,045 ; 0,061 ; 0,017 ; 0,015 ; 0,039 ; 0,02$; $0,026 ; 0,028 ; 0,029)$ yang dapat diartikan sebagai sedikit. Ada 16 ikan yang termasuk kelompok ini, yaitu ikan Tembang, Tonkogkol krai, Kembung, Madidihang, Julung, Lencam, Teri, Kakap, Kerapu, Baronang, Kwee, Tenggiri, Biji nangka, Selar, Swanggi, dan Lolosi biru.

2. Cluster kedua memiliki pusat $(0,794 ; 0,964$ 0,$977 ; 0,965 ; 0,929 ; 0,744 ; 0,705 ; 0,975 ; 0,722$; $0,839 ; 0,765 ; 0,787)$ yang dapat diartikan sebagai banyak. Ada 2 ikan yang termasuk dalam kelompok ini yaitu ikan Layang dan Cakalang.

Tabel 4 Posisi Cluster Iterasi Terakhir Tahun 2017

\begin{tabular}{|c|l|l|l|c|}
\hline No & Jenis Ikan & \multicolumn{1}{|c|}{$\mathbf{C}_{1}$} & $\mathbf{C} 2$ & $\begin{array}{c}\text { Posisi } \\
\text { Cluster }\end{array}$ \\
\hline 1 & Layang & 1,627 & 1,065 & $\mathbf{C 2}$ \\
\hline 2 & Tembang & 0,159 & 2,478 & C1 \\
\hline 3 & Cakalang & 3,23 & 1,065 & C2 \\
\hline 4 & Tongkol krai & 0,572 & 1,979 & C1 \\
\hline 5 & Kembung & 0,161 & 2,296 & C1 \\
\hline 6 & Madidihang & 0,655 & 1,732 & C1 \\
\hline 7 & Julung & 0,155 & 2,471 & C1 \\
\hline 8 & Lencam & 0,068 & 2,265 & C1 \\
\hline 9 & Teri & 0,179 & 2,496 & C1 \\
\hline 10 & Kakap & 0,077 & 2,256 & C1 \\
\hline 11 & Kerapu & 0,054 & 2,277 & C1 \\
\hline 12 & Baronang & 0,17 & 2,484 & C1 \\
\hline 13 & Kwee & 0,059 & 2,275 & C1 \\
\hline 14 & Tenggiri & 0,163 & 2,480 & C1 \\
\hline 15 & Biji nanggka & 0,156 & 2,473 & C1 \\
\hline 16 & Selar & 0,161 & 2,476 & C1 \\
\hline 17 & Swanggi & 0,16 & 2,473 & C1 \\
\hline 18 & Lolosi biru & 0,07 & 2,351 & C1 \\
\hline
\end{tabular}

Deskripsi:

1. Cluster pertama memiliki pusat $(0,04 ; 0,031$; 0,$037 ; 0,053 ; 0,059 ; 0,045 ; 0,036 ; 0,031 ; 0,046$; $0,063 ; 0,084 ; 0,068)$ yang dapat diartikan sebagai sedikit. Ada 16 ikan yang termasuk kelompok ini, yaitu ikan Tembang, Tongkol krai, Kembung, Madidihang, Julung, Lencam, Teri, Kakap, Kerapu, Baronang, Kwee, Tenggiri, Biji nangka, Selar, Swanggi, dan Lolosi biru.

2. Cluster kedua memiliki pusat $(0,716 ; 0,596$; 0,$918 ; 0,664 ; 0,754 ; 0,632 ; 0,66 ; 0,633 ; 0,591$; $0,872 ; 0,869 ; 0,65)$ yang dapat diartikan sebagai banyak. Ada 2 ikan yang termasuk dalam kelompok ini yaitu ikan Layang dan Cakalang.

$$
\text { V. PENUTUP }
$$

5.1. Kesimpulan

Berdasarkan hasil penelitian dalam clustering hasil tangkap ikan menggunakan $k$-means, dapat disimpulkan bahwa:

1. Algoritma K-Means telah digunakan untuk mengelompokkan hasil tangkap ikan periode 2015-2017 dengan menggunakan 2 cluster, yaitu cluster satu dikategorikan sebagai hasil tangkap sedikit, dan cluster dua dikategorikan sebagai hasil tangkap paling banyak. Dengan memperoleh hasil akhir yaitu jenis ikan dapat dikelompokkan kedalam masing-masing cluster. Ada 16 Jenis ikan pada cluster satu $\left(\mathrm{C}_{2}\right)$ adalah ikan tembang, tongkol krai, kembung, madidihang, julung, lencam, teri, kakap, kerapu, baronang, kwee, tenggiri, biji nangka, selar, swanggi dan lolosi biru. Dan ada 2 jenis ikan pada cluster dua yaitu ikan layang dan cakalang. Maka dari itu dapat dilihat bahwa jenis ikan yang unggul adalah pada cluster dua $\left(\mathrm{C}_{2}\right)$.

2. K-means mempunyai kelemahan yang diakibatkan oleh penentuan pusat awal cluster atau centroid. Hasil cluster yang terbentuk dari algoritma $k$-means sangatlah bergantung pada inisiasi nilai pusat awal cluster yang ditentukan, hal ini menyebabkan sangat sulit memperoleh hasil centroid awal yang unik, sehingga peneliti menggunakan metode validasi DBI untuk mengevaluasi hasil clustering yang diperoleh.

3. Peneliti melakukan perhitungan beberapa cluster, yaitu 2 cluster, 3 cluster, 4 cluster, dan 5 cluster untuk menentukan perbandingan cluster terbaik dengan menggunakan metode validasi DBI (Davies Bouldin Index), hasil nilai yang diperoleh:

a. 2 Cluster menghasilkan nilai DBI pada tahun $2015=0,395$, tahun $2016=0,276$ dan tahun $2017=0,54$.

b. 3 Cluster menghasilkan nilai DBI pada tahun $2015=1,126$, tahun $2016=0,541$, dan tahun $2017=0,692$.

c. 4 Cluster menghasilkan nilai DBI pada tahun $2015=2,052$, tahun $2016=0,704$, dan tahun $2017=0,568$. 
d. 5 Cluster menghasilkan nilai DBI pada tahun $2015=0,734$, tahun $2016=0,715$, dan tahun $2017=0,755$.

Jika nilai DBI mendekati nilai 0 maka cluster tersebut dianggap baik, pada option a sampai d terlihat bahawa nilai DBI pada 2 cluster tahun 2015 sampai 2017 adalah yang paling mendekati nilai 0 , maka 2 cluster yang dipakai pada penelitian ini dapat dinyatakan baik dibandingkan dengan beberapa cluster lainnya.

4. Perhitungan algoritma telah diimplementasikan pada aplikasi yang dibangun menggunakan bahasa program PHP hasilnya sama dengan perhitungan yang dilakukan secara manual.

5.2. Saran

1. Penelitian ini menggunakan algoritma $K$ means dan telah diketahui apa kelemahannya, diharapkan pada penelitian selanjutnya agar menggunakan algoritma lainnya, kemudian bandingkan hasilnya.

2. Menggunakan metode validasi untuk evaluasi cluster lebih dari 1, agar mendapatkan hasil cluster yang lebih baik.

3. Sistem yang dibangun masih terdapat kekurangan dan keterbatasan, yaitu sistemnya masih terlihat sederhana dan hanya berfokus pada metode yang digunakan, bukan di desain interface-nya, jadi diharapkan pada peneliti selanjutnya agar bisa dikembangkan tampilan interfacenya lebih mudah digunakan.

4. Sistem yang bangun menggunakan bahasa program PHP, maka dari itu diharapkan pada peneliti selanjutnya dapat menggunakan bahasa program lainnya, misalnya bahasa program Java, Phyton.

\section{DAFTAR PUSTAKA}

[1] Edi Mirmanto, 2010. Komposisi Flora dan Struktur Hutan Alami di Pulau Ternate. Bidang Botani Pusat Penelitian Biologi -LIPI.

[2] Statistik Perikanan Tangkap PPN Ternate, 2015. Kementrian Kelautan dan Perikanan. Pelabuhan Perikanan Nusantara Ternate.

[3] Johan Oscar Ong, 2013. Implementasi Algoritma K-Means Clustering untuk Menentukan Strategi Marketing President University. President University.

[4] Dwi Novianti Nango, 2012. Penerapan Algoritma K-Means Untuk Clustering Data Anggaran pendapatan Belanja Daerah di Kabupaten. Universitas Negeri Gorontalo.

[5] Eni Irviani, 2018. Algoritma K-Means Clustering untuk Menentukan Nilai Gizi Balita. Universitas Bima Sarana Informatika.

[6] Alith Fajar Muhammad, 2018. Klasterisasi Proses Seleksi Pemain Menggunakan Algoritma K-Means (Study Kasus: Tim Hockey Kabupaten
Kendal). Jurusan Teknik Informatika FIK UDINUS.

[7] Akhmad Sholikhin dan Berliana Kusuma, 2013. Pembangunan Sistem Informasi Investarisasi Sekolah Pada Dinas Pendidikan Kabupaten Rembang Berbasis Web. Indonesia Jurnal on Networking and Security (IJNS).

[8] Vindhy Agus Setiawan, 2011. Analisis dan Perancangan Sistem Informasi Simpan Pinjam Pada LKM Gerembeng Bali. Sekolah Tinggi Manajemen Informatika dan Komputer Yogyakarta.

[9] Tempola, F., dan Assagaf, A, F. 2018. Clustering of Potency of Shrimp in Indonesia with K-Means Algorithm and Validation of Davies-Bouldin Index. International Conference on Science and Technology (ICST 2018).730-733. https://www.atlantis-press.com/proceedings/icst$\underline{18 / 55910933}$ : diakses 27 November 2018) 